\title{
The first Blalock-Taussig shunt
}

\author{
Denton A. Cooley, MD
}

Editor's Note-The following article is the first in a series of "Reflections of the Pioneers" highlighting the history of cardiac and thoracic surgical techniques that were and continue to be significant in the treatment of patients with cardiac and thoracic disease. These articles will summarize the how, why, and what happened at the first operation and an evaluation of the technique since inception.

Our first article in this series is written by one of the all time legends in cardiac surgery, Dr Denton Cooley, who was present at the first Blalock-Taussig anastomosis for a blue baby that was performed in the mid 1940s when he was an intern.

I hope our readership enjoys these "Reflections of the Pioneers," individuals who have much influence on what we do today.

\section{Lawrence H. Cohn, MD Editor}

“Al, Eileen's lips are a glorious pink color!" said Helen Taussig, MD, pediatrician at Johns Hopkins noted for congenital cardiac anomalies, excitedly. Were these words comparable to those of astronaut Neil Armstrong, "one giant leap for mankind" in introducing an era in human courage and exploration? As a participant in the surgical event at Johns Hopkins Hospital on November 29, 1944, and at the invitation of Lawrence Cohn, Editor of this Journal, I will relate some recollections of the historic first "blue baby" correction (Figure 1), which many consider the dawn of cardiac surgery.

By an unusual stroke of my personal luck, Dr Alfred Blalock had witnessed a tennis game in the courtyard at Hopkins' Hospital between me and a fellow third-year student, Lester Persky. To my surprise, he then invited me to join him and his family for a weekend at Gibson Island so that he could have an opponent for ping pong. That may have helped me as an aspiring surgeon. I served externships in surgery during my senior year to fill vacancies, as many of the house staff volunteered for military service during World War II.

After graduation from Hopkins School of Medicine, I received a personal invitation to join the surgical house staff as an intern. The benefits were not financial-no

From the Texas Heart Institute, Houston, Tex.

Address for reprints: Denton A. Cooley, MD, President Emeritus, Surgeon-in-Chief, Texas Heart Institute, 6770 Bertner Ave, Houston, TX 77030 (E-mail: jmiller@ heart.thi.tmc.edu).

J Thorac Cardiovasc Surg 2010;140:750-1

$0022-5223 / \$ 36.00$

Copyright (c) 2010 by The American Association for Thoracic Surgery doi:10.1016/j.jtcvs.2010.06.033

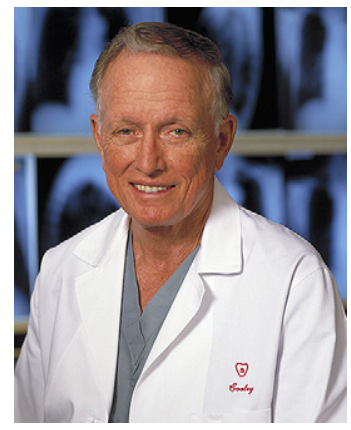

Denton A. Cooley, MD, President Emeritus and Surgeon-in-Chief, Texas Heart Institute.

salary at all, but free housing, food, uniforms, and laundry. My fellow intern, Hank Bahnson, was the first married intern and was given a special appointment despite that. Our confinement to the premises offered few social or recreational outlets. We considered ourselves privileged to be selected.

Having graduated on August 18, 1944, I joined the staff immediately for a straight surgical internship. My first rotation then was to provide fluid, blood, and plasma to support procedures in the operating rooms. That included responsibility for the blood bank and crossmatching of blood. I worked with one technician who enjoyed permanent employment. On the date of November 29, I arrived in scrub suit at 6:00 AM in the operating room for the scheduled procedure. Vivien Thomas, who was Dr Blalock's trusted technician from the Hunterian Laboratory (the dog lab), was there already. An air of tension was felt by all.

The patient, Eileen Saxon, a 2-year-old intensely cyanotic and frail child, was chosen as the first patient for trial of

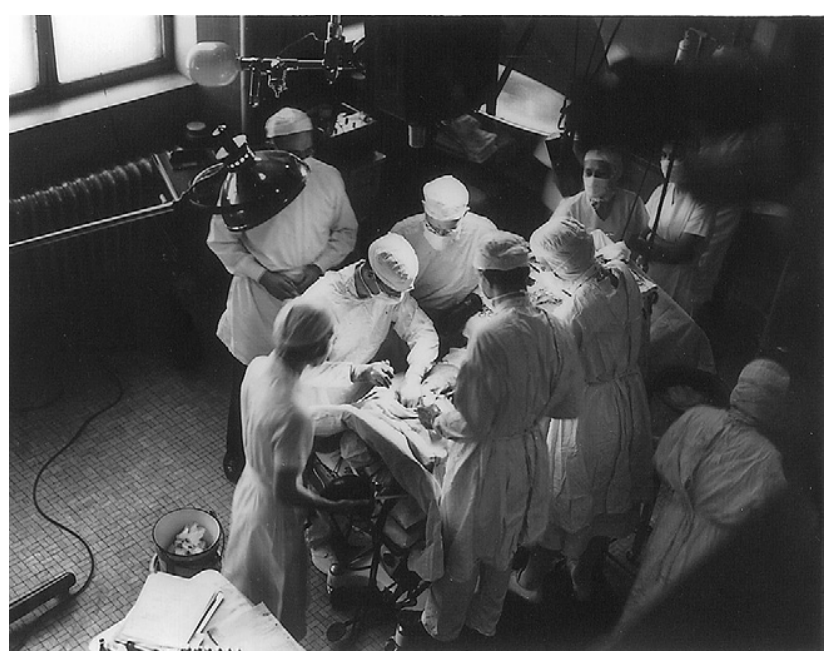

FIGURE 1. "Blue baby" operation, November 1944. Courtesy of Texas Heart Institute. 
a new and untested treatment for a congenital anomaly called tetralogy of Fallot. Most members of the medical and surgical staff questioned the plan to operate on this pathetic child. Anesthesia was a critical consideration, because no precedent was available. The newly appointed chief of anesthesiology, Dr Austin Lamont, actually declined the invitation, believing that the risk was too high and that induction itself could be fatal. He reluctantly assigned his junior associate, Dr Merel Harmel, to the task. Before this, all the anesthesia for Dr Blalock's operations had been provided by a nurse anesthetist, Olive Berger, in whom he had great confidence. Ether and oxygen were used with tracheal intubation, and the patient responded favorably, to everyone's relief. Vivien then withdrew blood from a femoral artery, a technique that only he was allowed to perform. He then determined the oxygen concentration with a VanSlyke apparatus. My duty was then to do a cutdown on the saphenous vein at the ankle and insert a cannula for infusion of glucose solution and possibly blood or plasma if needed.

When Dr Blalock arrived in the operating room, he courteously greeted the instrument nurse and the orderly, who were both members of the professor's team but whose names now escape me.

Dr Blalock took his position on the left side of the table, with Bill Longmire on the opposite side. Vivien stood behind Dr Blalock. Dr Taussig stood behind Harmel but was unable to witness the dissection. The incision was an anterolateral incision in the third interspace, and the second and third costal cartilages were divided. Exposure was limited by the incision, and I was unable to observe much. Because the aortic arch was on the left side, the subclavian artery was almost too short to pass over the arch into the left subclavian artery. Instruments were crude by today's standards and consisted of several bulldog clamps, which were encircled with silk threads to permit traction. Some of these techniques had been developed by Vivien in the dog lab. Dissection in the highly vascular mediastinum to isolate the left pulmonary artery was skillfully done by Dr Blalock with instruments and his left index finger. When the final preparation for the anastomosis was made, the end of the shortened subclavian artery was connected with fine black silk sutures to the side of the pulmonary artery. Dr Blalock several times asked Vivien for advice on suturing.

Finally, the tense moment came when the bulldogs were released and systemic blood was transferred into the pulmonary circulation. Although the immediate technical results were not very satisfying to Dr Blalock, the patient's color improved with inflation of the lung. A moment for "Hurrah!' occurred but was stifled by Dr Blalock's concern. He was disappointed that the expected continuous thrill was not palpable. The postoperative course was complicated by bilateral pneumothoraces, possibly from overinflation of the lungs. Indwelling pleural drains were not used because they were considered hazardous and a source of infection. After other complications, Eileen left the hospital about 2 weeks later, with her cyanosis only moderately improved. Weeks later, when the shunt became occluded, another shunt was attempted on the right side, but she did not survive. I have always considered Eileen Saxon as one of the real martyrs to surgical practice and history.

From that operation, which resulted from Dr Blalock's determined decision in the face of much opposition, much has since been achieved in cardiac and vascular surgery. Credit for the success of the conception for the procedure and the clinical performance was shared somewhat unequally at times thereafter but led to final, widespread use of the Blalock-Taussig concept and procedure. I am gratified to have been fortunate to participate in the original operation. But I shall always admire Dr Blalock for his courage and determination after Eileen's death to proceed with other patients. His critics were silenced. 